\title{
AS CONTEXTUALIZAÇÕES DA FOTOGRAFIA DE AYLAN KURDI E A QUEBRA DO PODER DO AUTOR
}

\author{
Thamires Ferreira dos Santos ${ }^{1}$, Luiz Carlos Dale Vedove ${ }^{2}$ \\ 'Universidade do Oeste Paulista - UNOESTE - Especialização em Literatura e Jornalismo: Práticas Textuais, Presidente \\ Prudente, SP. ${ }^{2}$ Universidade Estadual de Londrina - UEL, Mestrado em Comunicação Visual, Londrina, PR. Docente na \\ Pós-graduação em Literatura e Jornalismo, UNOESTE. E-mail: thamires fsnts@hotmail.com, luiz.dalle@gmail.com
}

\section{RESUMO}

O presente artigo pretende analisar as charges criadas a partir da fotografia de Aylan Kurdi, divulgadas nas redes sociais e, posteriormente, replicadas nos veículos de comunicação. $E$, assim, discutir como o pós-modernismo revela-se como uma importante ferramenta na propagação de imagens fortes que levam à reflexão, com ênfase no fenômeno da quebra do poder do autor.

Palavras-chave: fotografia, Aylan Kurdi, refugiados, redes sociais, charges.

\section{THE CONTEXTUALIZATIONS OF AYLAN KURDI'S PHOTOGRAPH AND THE BREAKING OF AUTHOR POWER}

\section{ABSTRACT}

This article aims to analyze the cartoons created based on the picture of Aylan Kurdi, published on social networks, and later replicated in the media. Therefore, to debate on how post-modernism proves to be an important tool in the propagation of Strong images that lead to reflection, giving emphasis on the phenomenon of the breaking of the power of the author.

Keywords: photography, Aylan Kurdi, refugees, social networks, cartoons. 


\section{INTRODUÇÃO}

Em 02 de setembro de 2015, a fotógrafa Nilüfer Demir, da agência de notícias DHA, da Turquia, fotografou o corpo de um menino na areia de uma praia: Aylan Kurdi, de 3 anos, afogado em uma tentativa de chegar à Europa. Essa imagem mudou os rumos (ou ao menos o destaque na imprensa) na crise migratória.

O menino, os pais e seu irmão Galip, de 5 anos, partiram de Bodrum, Turquia, com destino à ilha grega de Kos, de barco e com outros 13 imigrantes. Assim como outras milhares de pessoas do Afeganistão, Iraque, Nigéria e Somália, foram obrigados a arriscar suas vidas para escapar da guerra e da pobreza. A embarcação naufragou. Dessa família, apenas Abdullah Kurdi, pai de Aylan, sobreviveu. Outros nove sírios também não chegaram ao destino final da travessia.

Após a divulgação da imagem, muitos internautas reproduziram em suas Redes Sociais desenhos relacionados ao acontecimento, parte em forma de consternação pela morte de uma criança de modo atroz, parte criticando a resposta dos líderes europeus aos deslocamentos do Oriente Médio e da África. As pessoas se expressaram em charges pelo Twitter e Facebook, e os veículos de comunicação replicaram as imagens nas plataformas on-line.

Neste artigo será analisada a publicação das charges relacionadas à fotografia do menino Aylan Kurdi, a partir das apreciações de alguns teóricos, visando relacioná-las aos conceitos de pós-modernidade, ao apresentar algumas reproduções dos veículos jornalísticos.

\section{METODOLOGIA}

Este estudo objetiva analisar por meio da pesquisa bibliográfica a utilização das charges ou ilustrações relacionadas à fotografia de Aylan Kurdi. Conforme Fonseca (2002) existem pesquisas científicas que baseiam-se unicamente na pesquisa bibliográfica, "procurando referências teóricas publicadas com o objetivo de recolher informações ou conhecimentos prévios sobre o problema a respeito do qual se procura a resposta". (FONSECA, 2002, p. 32)

Sendo assim, como referencial teórico ter-se-á as ideias de pós-modernidade de David Harvey (1989) e Stephen R. C Hicks (2011). Os conceitos de Zygmunt Bauman (2004) serão utilizados para tratar da crise dos refugiados e as considerações de Susan Sontag (2003), relativas ao uso das fotografias de impacto, embasarão as hipóteses referentes a forma dos veículos de comunicação de repercutir os desdobramentos provocados pela imagem.

Este estudo optou por analisar a seleção de imagens publicadas nos sites: $\mathrm{Uol}{ }^{1}, \mathrm{G} 1^{2}, \mathrm{R} 7^{3} \mathrm{e}$ Band.com ${ }^{4}$ que, em tese, tiveram o mesmo critério de seleção, pois reproduziram as publicações que levavam a hashtag \#KiyiyaVuranInsanlik (humanidade levada com as águas), pode-se afirmar que este estudo descritivo seguirá os procedimentos de uma pesquisa ex-post-facto. Visto que:

A pesquisa ex-post-facto tem por objetivo investigar possíveis relações de causa e efeito entre um determinado fato identificado pelo pesquisador e um fenômeno que ocorre posteriormente. A principal característica deste tipo de pesquisa é o fato de os dados serem coletados após a ocorrência dos eventos. (FONSECA, 2002, p. 32).

O fator que melhor caracteriza essa pesquisa descritiva está no fotojornalismo integrar o Hardnews, e os fenômenos das Redes Sociais serem instantâneos aos acontecimentos, assim a

\footnotetext{
${ }^{1}$ http://noticias.uol.com.br/album/2015/09/03/charges-reagem-a-morte-de-menino-refugiado.htm\#fotoNav=4

${ }^{2}$ http://g1.globo.com/mundo/noticia/2015/09/ilustracoes-homenageiam-menino-sirio-morto-em-praia-em-redes-sociais.html

${ }^{3}$ http://noticias.r7.com/internacional/menino-que-se-afogou-no-mar-egeu-e-enterrado-em-cidade-disputada-pelo-estado-islamico-04092015

${ }^{4}$ http://www.band.uol.com.br/m/conteudo.asp?id=/100000774664/\&programa=/Mundo/\&editoria=/Noticias/\#foto1 
fotografia de Aylan Kurdi estabeleceu com o público um diálogo imediato, e despertou a necessidade de recriar uma nova história a partir daquela imagem.

A partir da definição de Harvey (1989, p.53), observa-se um fenômeno típico do período pós-moderno, uma vez que para os pós-modernistas os leitores têm intersecção livre em um texto e podem se apropriar deles, isto é, tem liberdade para alterar qualquer mensagem.

\section{RESULTADOS}

A fotografia é a forma de informação visual mais tradicional do jornalismo. Algumas alçaram o patamar de obras de arte, tamanho o reconhecimento da importância delas e a valorização do trabalho do fotojornalista. Segundo Dubois (1993, p. 53), qualquer análise de imagem é "como uma interpretação-transformação do real, como uma formação arbitrária, cultural, ideológica e perceptualmente codificada".

Após a fotógrafa Nilüfer Demir registrar as imagens do corpo de Aylan kurdi (Figura 01), disse em entrevista ao G1 ter pensado que poderia trazer à tona o clamor daquela criança.

\section{Figura 01.}

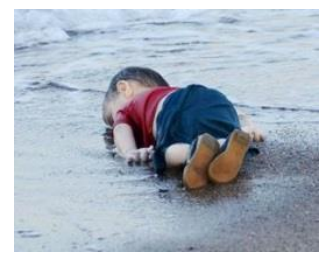

Fonte: Times ofIndia (2015)

Sontag $(2003$, p.12) resume perfeitamente o sentimento da fotógrafa ao teorizar sobre a criação de fotografias de choque como essa: "As fotos são o meio de tornar 'real' (ou 'mais real') assuntos que as pessoas socialmente privilegiadas, ou simplesmente em segurança, talvez preferissem ignorar". Não são raras as situações em que se veem, por meio da fotografia, as mazelas de outras pessoas. A autora pontua que "fotos de uma atrocidade podem suscitar reações opostas. Um apelo em favor da paz. Um clamor de vingança. Ou apenas a atordoada consciência, continuamente reabastecida por informações fotográficas, de que coisas terríveis acontecem" (SONTAG, 2003, p.16). Convenientemente foi isto que aconteceu.

Inúmeros desenhistas, amadores e profissionais, ao redor do globo, fizeram desenhos em homenagem a Aylan Kurdi. Para começar têm-se duas comparações entre a publicação original e a compartilhada.

A primeira é uma ilustração do cartunista egípcio Islam Gawish. Nela há uma reprodução da imagem da criança com o rosto enterrado na areia da praia, com o acréscimo de uma rosa e de asas. Na versão original da imagem, encontrada na rede social do artista, há ainda a palavra "Síria" em vermelho-sangue. O cartunista declarou na época: "Esta criança que queria liberdade foi morta pelo medo da guerra, guerra que ela não fazia parte".
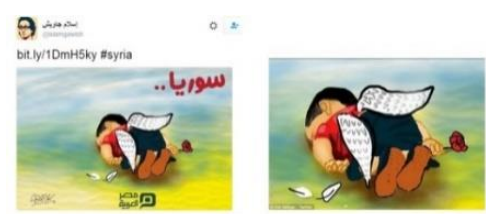

Figura 02. À esquerda: Print Scream da rede social do cartunista, à direita: imagem reproduzida nos sites jornalísticos analisados;

Fonte: Twitter (2015) e G1.com (2015); Twitter (2015) e R7.com (2015)

Pode-se identificar o sentimento de consternação do cartunista ao fazer uma releitura romântica da imagem. O R7 associou à página em que foram compiladas as charges uma 
entrevista com o cientista político Heni Ozi Cukier afirmando que o compartilhamento da fotografia é negativo, apesar de fomentar o debate. "Estamos trazendo leigos para dentro de uma discussão, que vão ficar fazendo mais barulho e simplificar o debate. A imagem só consegue passar um aspecto emotivo do que está acontecendo, mas não explica o contexto". (R7, 2015a)

$O$ veículo informativo assume a necessidade de contextualização, no entanto, através das declarações de um especialista, justifica não reproduzir a foto original. $E$, ao compartilhar as postagens dos internautas, não atribui créditos ou legendas além daquelas feitas pelos próprios internautas.

Ainda conforme o entrevistado pelo R7, a foto de Aylan expõe a realidade. Todavia, mesmo uma mobilização gigantesca não evolui além do discurso apaixonado. Para o R7 o "Garotinho síriocurdo se transformou em símbolo do desastre humanitário envolvendo os refugiados do mundo inteiro" (R7, 2015b), por isso merece destaque no noticiário. Entretanto, as vítimas que vieram antes não tiveram fotografias tão marcantes, e aquelas que vieram depois não eram mais novidade. Esta imagem foi divulgada pelos sites jornalísticos, ora sem a legenda e o crédito do autor, ora a reprodução da imagem na rede social de outro usuário.

Conforme Sontag (2003) os produtores de conteúdo jornalístico tomam diariamente decisões que consolidam o consenso do "bom gosto". Faz sentido, se entendida como respeito aos anseios da ordem e da moral pública, e também como um indício da incapacidade de lamentar as mortes de outra maneira, pois, como observa Sontag (2003, p. 60), "o que se pode mostrar, o que não se deveria mostrar - poucas questões suscitam um clamor público mais forte". Daí a preferência dada pelas charges à fotografia em si.

A terceira imagem (Figura 3) selecionada para este estudo é de Murat Sayin. O artista acrescentou um barquinho de papel e o nascer do sol ao cenário da tragédia. O ilustrador natural de Ancara, Turquia, declarou: "vendo uma criança morta em uma praia, em um país que supostamente lhe daria refúgio e futuro, uma criança que estava fugindo da guerra e da morte".

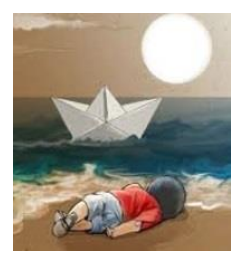

Figura 03.

Fonte: Uol.com (2015)

A declaração apresentada acima foi retirada da página da CNN norte americana ${ }^{5}$. A CNN entrevistou todos os cartunistas mencionados neste estudo (confira no link na nota de rodapé), e isto sinaliza o pouco interesse dos sites jornalísticos brasileiros em encontrar o autor das imagens replicadas por eles. Para esta charge o Uol usou a seguinte legenda: "Barco de papel navega próximo a corpo de menino morto afogado", e o crédito foi "Imagem: Twitter/Reprodução".

Por medo de perder o imediatismo, os sites brasileiros fragmentaram a informação, e criaram compilações na tentativa de aproximar os veículos do público. O mesmo descaso com a fonte pode ser constatado nos demais sites analisados. Para Aquino, Duarte e Campos (2012), a internet é um meio de comunicação que apresenta para os profissionais de comunicação pontos positivos e negativos. Pois, a interação mudou na medida em que os meios foram mudando.

Ficou mais fácil publicar artigos, opiniões, e ao mesmo tempo, se preocupar com causas sociais [...]. Tudo sem sair da frente da tela. A força das mídias sociais é tão grande que hoje ficamos sabendo do que acontece

\footnotetext{
${ }^{5}$ http://edition.cnn.com/2015/09/03/world/syrian-boy-artist-tributes/
} 
na Internet sem precisamente estar conectado, seja por comentários ou por reprodução na TV. (AQUINO; DURANTE; CAMPOS; 2012, p.9)

Em clara referência a dificuldade de conseguir vistos ou asilo político a fim de escapar da guerra, na Figura 4, do sudanês Khalid Albaih, o anjo diz: "espero que a humanidade descubra a cura para os vistos".

\section{Figura 04.}

Fonte: R7.com (2015)

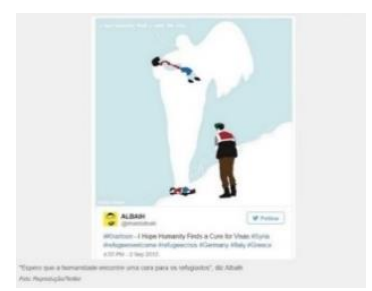

Segundo Bauman (2004, p.74), as nações mais poderosas, que forçavam os estrangeiros a assimilarem sua própria cultura, passaram a expeli-los, e, essa estratégia de deportações e expulsões criam imagens de televisão dramáticas e chegam a desencadear clamores do público. Logo, os governos preferem recusar estrangeiros, reduzindo o direito de asilo político. "Essa tendência assinala não uma nova estratégia com relação ao fenômeno dos refugiados, mas uma ausência de estratégia" (BAUMAN, 2004, p.74).

Desde o século VII a humanidade debate publicamente o problema dos chamados "les malheureux", no século seguinte denominados "les misérables", até assumir a alcunha "refugiados". Bauman (2004, p.71) conclui que as nomenclaturas mudaram, todavia, sempre foram sobre aqueles "privados de um lugar próprio no mapa-múndi mental desenhado pelos povos que cunhavam e empregavam esses nomes".

A ideia de mapa-mundi mencionada por Bauman aparece na Figura 7. Em vez da clássica representação dos continentes, há também o menino. Seu corpo flutua "às margens" do mundo, uma vez que há um muro com arame farpado isolando-o da terra firme. A autoria desta charge foi negligenciada pelos sites jornalísticos brasileiros, assim como nos casos anteriores.

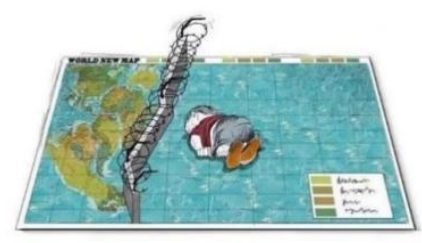

Figura 07.

Fonte: Uol.com (2015)

Rafat Alkhateeb é cartunista do Nesan News de Amã (Jordãnia). Segundo Alkhateeb, em entrevista para a revista "TakePark" ${ }^{6}$ da Califórnia (EUA), o "Novo Mapa do Mundo" mostra que todos tem "plena responsabilidade" pela morte da criança. "As pessoas podem se envolver emocionalmente, neste caso, sem reflexão sobre a realidade, se só continuarem postando fotos e fornecendo os melhores comentários sobre ele, esquecendo a própria criança". (ALKHATEEB, 2015)

Sontag (2003) conceitua que a mídia determina com quem a sociedade se importará, porque apenas quando há registros visuais, uma guerra se torna real. "As imagens têm sido

\footnotetext{
${ }^{6}$ http://www.takepart.com/article/2015/09/03/artists-around-world-illustrate-why-syrian-toddler-death-matters 
criticadas por representarem um modo de ver o sofrimento à distância, como se existisse outro modo de ver". (SONTAG, 2003, p.98)

Conclui-se que houve uma espécie de manifesto ecoando nos traços artísticos publicados nas redes sociais. Conforme Dubois (1993) a arte não tem pretensão de ser mimética, quer o artista queira, quer não, os desenhos transitam inevitavelmente por meio de uma individualidade. "Por isso, por mais 'objetivo' ou 'realista' que se pretenda, o sujeito pintor faz a imagem passar por uma visão, uma interpretação, uma maneira, uma estruturação, em suma, por uma presença humana que sempre marcará o quadro". (DUBOIS, 1993, p.32)

\section{CONSIDERAÇÕES FINAIS}

É fato que as fotografias de Aylan Kurdi retratam uma fração do conflito entre o Estado islâmico e as forças curdas e da insegurança no Mediterrâneo. Mas, no caso das releituras selecionadas para este artigo percebe-se que diante de uma notícia insólita, abriu-se caminho para crescimento social, experimentado aqui em forma de charges e da própria fotografia, em que os veículos de comunicação optaram por privilegiar a repercussão do caso.

O pós-modernismo revela-se uma máscara que esconde o repugnante:

O movimento pós-moderno contém muitas pessoas que gostam da ideia de descontruir o trabalho criativo de outras. A desconstrução tem o efeito de nivelar qualquer significado e valor. Se um texto pode significar alguma coisa, então não significa nada mais que qualquer outra coisa - nenhum texto, portanto, é grandioso. (HICKS, 2011, p.231)

O efeito disso é a minimização da autoridade do autor. O produtor do conteúdo apenas fornece fragmentos. "Cria a oportunidade de participação popular [...] uma certa vulnerabilidade à manipulação do mercado de massa" (HARVEY, 1989, p.55). Exatamente como visto no caso da publicação de charges tiradas das redes sociais para as páginas jornalísticas.

O pós-modernismo rejeita a realidade, substituindo-a. Os internautas e os sites jornalísticos são parte do movimento pós-moderno, tanto que escolhem as representações em lugar da verdade e aprendem ou se engajam, a partir dessas construções.

De acordo com o Hicks (2011), nos debates pós-modernos a dita "Verdade" é um mito. Com o fim das verdades absolutas, surgem inúmeras interpretações, há um entrelaçamento intertextual. Apropriações, paródias, repetições, releituras, etc., vão sendo replicadas e, ainda assim, são insuficientes para explicar a complexidade das realidades sociais. Tudo possibilita originar uma proposição, uma ideia ou uma ação, e o real pode sim ser colocado em dúvida, mas nunca mascarado. Não há fatos, apenas reproduções, ou interpretações. Impera a indeterminação.

\section{REFERÊNCIAS}

ALKHATEEB, Rafat. Artists Around the World Illustrate Why That Syrian Toddler's Death Matters [set. 2015]. DWYER, Liz. Califórnia: Takepart, 03 set. 2015. Site. Revista de notícias, com jornalismo independente sobre os mais importantes temas da atualidade, socialmente relevantes.

AQUINO, Marcelo de Souza; DURANTE, Paola Carleto; CAMPOS, Camila Craveiro da Costa. O Poder das Mídias Sociais. In: CONGRESSO DE CIÊNCIAS DA COMUNICAÇÃO NA REGIÃO CENTRO-OESTE, 14.,2012, Campo Grande. Anais...Goiânia: Uni-Anhanguera, 2012. Disponível em: <http://www.intercom.org.br/papers/regionais/centrooeste2012/resumos/R31-0214-1.pdf>. Acesso em: 05 ago. 2016 
BAUMAN, Zygmunt. Amor líquido: sobre a fragilidade dos laços humanos. Rio de Janeiro: Jorge Zahar Editora, 2004.

DUBOIS, Philippe. O ato fotográfico e outros ensaios. 2. ed. Campinas: Papirus, 1993.

FONSECA, João José Saraiva da. Metodologia da pesquisa científica. Fortaleza: UEC, 2002. Apostila.

HARVEY, David. Condição pós-moderna. 16. ed. São Paulo: Edições Loyola, 2007. cap. 2:

Modernidade e modernismo, p. 21-44

HICKS, Stephen Ronald Craig. Explicando o Pós-modernismo: ceticismo e socialismo, de Rosseau a Focault. São Paulo: Callis, 2011.

R7. Notícias. Compartilhar foto de menino refugiado morto ajuda a prolongar a guerra, diz especialista. 2015a. Disponível em: < http://noticias.r7.com/internacional/compartilhar-foto-demenino-refugiado-morto-ajuda-a-prolongar-a-guerra-diz-especialista-04092015>. Acesso em: 05 ago. 2016.

R7. Notícias. Menino que se afogou no Mar Egeu é enterrado em cidade disputada pelo Estado Islâmico. 2015b. Disponível em: < http://noticias.r7.com/internacional/menino-que-se-afogou-nomar-egeu-e-enterrado-em-cidade-disputada-pelo-estado-islamico-04092015

>. Acesso em: 05 ago. 2016. 